\title{
SEIS DÉCADAS DE UM PROJETO DE PLENA DEMOCRATIZAÇÃO: REATUALIZANDO A ATUALIDADE BRASILEIRA COM PAULO FREIRE
}

\author{
LUIZ FERNANDO DE OLIVEIRA ${ }^{1}$ \\ ORCID: https://orcid.org/0000-0003-2532-1831
}

\begin{abstract}
RESUMO: Apresenta-se aqui uma análise contextual e atualizada da obra Educação e atualidade brasileira, escrita por Paulo Freire em 1959, na qual o autor mostra como o contraste entre a "inexperiência democrática" e a "emersão do povo na vida pública nacional" constituía a antinomia fundamental do Brasil "em desenvolvimento". Por meio de um retrospecto histórico, aponta, na própria formação do Brasil, as origens das disposições mentais antidemocráticas do seu povo e os processos pelos quais essas disposições se perpetuaram. Identificando no fim da década de 1950 as circunstâncias propícias para a inserção participativa e crítica do povo nos processos decisórios nacionais, o autor defende a necessidade de se formar as mulheres e os homens para a vida democrática, papel de uma educação que necessitava de uma completa revisão. Consideradas as especificidades de cada momento, as reflexões de Freire lançam luzes sobre a contexto atual, amparam a problematização de suas antinomias e revelam os caminhos pelos quais se pode construir uma educação para a justiça social.
\end{abstract}

Palavras-chave: Educação para a democracia, antinomia fundamental, colonização de exploração, criticidade.

\section{SIX DECADES OF A FULL DEMOCRATIZATION PROJECT: UPDATING BRAZILIAN CURRENTNESS WITH PAULO FREIRE}

\begin{abstract}
This article presents a contextual and updated analysis of the book Educação e atualidade brasileira (Education and Brazilian actuality), written by Paulo Freire in 1959, in which the author demonstrates how the contrast between the "democratic inexperience" and the "people emergence to national public life" formed the fundamental antinomy of Brazil in developing. Through a historical approach, Freire detects the origin of the anti-democratic mental dispositions of Brazilian people in Brazil formation itself. He also points out the processes that afforded the perpetuation of these anti-democratic mental dispositions. Detecting the end of the 1950s as the propitious scenario for a participative and critical insertion of people in the decision-making national processes, the author supports the necessity of educating women and men to democratic life, the role of an education that needed a complete revision. Considering the specificities of each historical moment, Freire's reflections enlighten the current context, support the problematization of nowadays antinomies, and reveal the paths in which it is possible to build one education for social justice.
\end{abstract}

Keywords: Democracy education, fundamental antinomy, exploration and colonization, criticality.

1 Centro Federal de Educação Tecnológica de Minas Gerais (CEFET-MG). Nepomuceno, MG, Brasil. <luizfernandodeoliveira@gmail.com>, <luizf@cefetmg.br>

Educação em Revista|Belo Horizonte|v.36|e233695|2020 


\section{SEIS DÉCADAS DE UN PROYECTO DE PLENA DEMOCRATIZACIÓN: REACTUALIZANDO LA ACTUALIDAD BRASILEÑA CON PAULO FREIRE}

RESÚMEN: Se presenta un análisis contextual y actualizado de la obra Educación y la actualidad brasileña, escrita por Paulo Freire en 1959, en la cual el escritor demuestra como el contraste entre la "inexperiencia democrática" y la "emersión del pueblo en la vida pública nacional" constituyó la antinomia fundamental del Brasil "en desarrollo". Por medio de una retrospección histórica, señala, en la propia formación de Brasil, los orígenes de las disposiciones mentales antidemocráticas de su pueblo y los procesos por los cuales estas disposiciones se perpetuaron. Identificando, en el fin de la década de 1950, las circunstancias favorables para la inserción participativa y crítica del pueblo en los procesos decisorios nacionales, el escritor defiende la necesidad de formarse mujeres y hombres para la vida democrática, un rol de una educación que necesitaba una revisión completa. Consideradas las especificidades de cada momento, las reflexiones de Freire traen luz al actual contexto, apoyando la problematización de sus antinomias y revelando los caminos por los cuales se puede construir una educación para la justicia social.

Palabras clave: Educación para la democracia, antinomia fundamental, colonización de exploración, criticidad. 


\section{INTRODUÇÃO}

Problematizar os vínculos entre a educação, escolar e não-escolar, e os processos sociais, políticos e econômicos é desafiador, mais ainda em países como o Brasil, dadas a complexidade cultural e as profundas desigualdades que o constituem. Todavia, o esforço é justificável, em razão mesma dessas desigualdades, as quais foram se agravando no decorrer da história nacional, adquiriram outras formas, diversificaram-se em novos matizes. Passíveis de superação, seu enfrentamento radical ainda não se efetivou, tendo se perdido, até os dias atuais, em meio a tímidos e pontuais avanços mal distribuídos no tempo e no espaço geográfico, ou tendo sido refreado por retrocessos de ordem política e jurídica, quando não foi completamente sufocado nos momentos de explícita ruptura democrática.

Educação e atualidade brasileira é um trabalho de Paulo Freire (1921-1997) escrito em 1959, portanto, há seis décadas, e que, em detrimento desse espaço temporal, apresenta-se como um instrumento consistente a partir do qual é possível analisar a realidade socio-educacional brasileira do momento presente. Nessa obra o autor reflete com rigor sobre os vínculos existentes entre a educação e os processos políticos, econômicos e sociais mais amplos, faz uma crítica contundente da forma como esses vínculos estavam sendo instrumentalizados e vislumbra e propõe um tratamento mais inclusivo e democrático deles. Trata-se da tese defendida pelo autor em um concurso para a cadeira de História e Filosofia da Educação da Escola de Belas-Artes de Pernambuco, e que constitui o seu primeiro texto de maior fôlego, aqui analisado em sua reedição póstuma (FREIRE, 2001).

Nesse trabalho o autor conseguiu captar com acuidade os elementos circunstanciais que, naquele momento, a virada da década de 1950 para a de 1960, mostravam-se como forças capazes de se consumar em um projeto verdadeiramente democrático de nação, embora pudessem se desvirtuar - dada a indeterminação dos processos históricos - e culminar em um projeto oposto, de aprofundamento das desigualdades em um país historicamente desigual.

O estudo se caracteriza por uma abordagem amparada em um referencial bibliográfico relativamente heterogêneo, tanto no que se refere aos campos de atuação dos autores trazidos por Freire, quanto no tocante ao posicionamento político desses autores: educadores como Anísio Teixeira e Fernando Azevedo, os filósofos Gabriel Marcel, Jacques Maritain e Simone Weil, cientistas sociais como Gilberto Freyre e Karl Mannheim, o escritor Aldous Huxley e o padre jesuíta Antônio Vieira, apenas para mencionar alguns exemplos, dão a tônica dessa heterogeneidade. Entretanto, o então jovem Freire encontra uma coerência na pluralidade desse referencial, que além de não soar internamente contraditório ou incoerente, ainda desperta o interesse para o entendimento da forma como o seu pensamento se construía (ROMÃO, 2001). Embora estivesse nos primórdios da elaboração de sua teoria, o autor consegue, na obra aqui analisada, apresentar um texto coeso, denso e literariamente belo, em consonância com o que viria a ser a sua obra da maturidade e à altura desta.

Ainda a respeito do referencial bibliográfico, vale mencionar a atenção de Freire aos trabalhos realizados pelo Instituto Superior de Estudos Brasileiros (ISEB), órgão do Ministério da Educação e Cultura criado pelo Decreto no 37.608, de 14 de julho de 1955, no governo do presidente Café Filho (1954-1955). O objetivo principal do ISEB era difundir o estudo e o ensino das Ciências Sociais aplicadas à compreensão crítica da realidade brasileira. Os intelectuais do ISEB entendiam que o caminho para que o país superasse o seu subdesenvolvimento seria o da industrialização. Todavia, sob a liderança de novas forças políticas, representadas pela burguesia industrial nacional com o apoio do proletariado, único meio de fortalecer a indústria brasileira na luta contra as investidas do capital estrangeiro, em uma postura marcadamente nacionalista, que não necessariamente encontrou ecos correspondentes no governo seguinte, o de Juscelino Kubitschek (1956-1961). Do mesmo modo, alguns grupos de intelectuais ligados a grandes universidades do país passaram a deslegitimar o conhecimento produzido pelo ISEB, dada a formação acadêmica de seus integrantes, basicamente advogados com conhecimento filosófico, ao menos supostamente desprovidos de um cabedal teórico-metodológico necessário à produção de conhecimentos científicos sobre a sociedade brasileira. Além disso, determinados veículos da imprensa brasileira bem como representantes do empresariado nacional mais ligado aos interesses estrangeiros passaram a identificar o ISEB com movimentos "esquerdistas" e "comunistas", o que contribuiu para que a representação do grupo frente à sociedade fosse sendo comprometida. A aparente homogeneidade 
da orientação política dos intelectuais do ISEB foi rompida definitivamente ainda no final da década de 1950. Seus membros mais radicalmente nacionalistas passaram a se opor fortemente aos que entendiam que fosse necessária alguma abertura ao capital estrangeiro, estes, mais alinhados ao plano político do governo federal. De qualquer forma, o ISEB foi extinto em 13 de abril de 1964, pelos militares que depuseram o então presidente João Goulart (ABREU, s/d; BRESSER-PEREIRA, 2004; PAIVA, 2005; TOLEDO, 1998). Embora fuja ao escopo do presente trabalho uma discussão detida sobre as contribuições dos então chamados "isebianos", o fato é que Freire foi um entusiasta das ideias desse grupo, o que transparece na quantidade de autores a ele ligados que aparecem na obra aqui analisada, bem como na forma elogiosa como costuma a eles se referir ao longo do texto. Entre os intelectuais que fizeram parte do ISEB, Freire (2001) busca embasamento em Álvaro Vieira Pinto, Djacir Menezes, Guerreiro Ramos, Hélio Jaguaribe, Nelson Werneck Sodré, Roberto Campos, Roland Corbisier e Temístocles Cavalcanti.

O pensamento freiriano foi fortemente influenciado, vale ainda mencionar, pelo Catolicismo Romano, religião professada pelo autor, sobretudo por suas vertentes mais progressistas, voltadas a uma espiritualidade engajada com questões sociais concretas e que, a partir de meados da década de 1960, comporiam a chamada Teologia da Libertação. Desde o surgimento da Teologia da Libertação, Paulo Freire manteve estreito contato com teólogos brasileiros e latino-americanos, de um modo geral, dessa vertente católica, influenciando-os e por eles sendo influenciado ${ }^{2}$. De fato, todo o corpus do pensador pernambucano, desde Educação e atualidade brasileira, é perpassado por um elemento marcante da cultura judaico-cristã: profetismo, entendido como o comprometimento pessoal com a denúncia das situações desumanizantes e com o anúncio de um projeto de humanização (BEISIEGEL, 2010; BRIGHENTE; MESQUIDA, 2016; COSTA, 2015; FREIRE, 1978; MENDONÇA, 2006; OLIVEIRA, 2004; ZITKOSKI, 2010). Por estranho, posto que ousado, que possa parecer, no caso de um trabalho acadêmico, já na obra aqui analisada o autor explicita a sua fé engajada quando afirma o caráter necessariamente dialogal do homem, o que envolve "uma dialogação eterna do homem com o homem, do homem com a circunstância. Do homem com o seu Criador" (FREIRE, 2001, p. 35. Grifo meu). Esse profetismo histórico-místico perpassa toda a obra de Freire, e lhe rendeu, inclusive, pelo menos uma obra especificamente dedicada ao tema, Os cristãos e a libertação dos oprimidos (FREIRE, 1978).

A respeito da escrita, Educação e atualidade brasileira segue o estilo ensaístico que viria a marcar toda a obra de Freire. Porém, ainda que não tenha desenvolvido um trabalho acadêmico pautado em um material empírico sistematicamente coletado, ancorado em uma metodologia explícita e específica de campo, o autor aponta, em diversos momentos, que a sua experiência pessoal pôde lhe fornecer dados capazes de respaldar as posições por ele defendidas. Na obra, o autor faz menção a um trabalho educativo de envolvimento de operários com os problemas que lhes eram comuns, desenvolvido sob sua orientação no âmbito do Serviço Social da Indústria (SESI) de Pernambuco ${ }^{3}$, e a uma experiência semelhante em um "zona paroquial", a de Casa Amarela, no Recife (FREIRE, 2001, p. 115). Estas duas experiências que, com o devido cuidado, podem ser consideradas a "empiria" do trabalho, consistiram na organização de grupos de operários e/ou moradores, com vistas ao levantamento dos problemas locais e à responsabilização desses operários/moradores pela resolução de tais problemas a partir do exercício do diálogo. Nas palavras de Freire (2001, p. 21), a sua experiência, embora restrita aos limites do Sesi a da zona paroquial de Casa Amarela, o "autoriza a falar positivamente de um trabalho educativo desta ordem”.

Há um triplo movimento na obra: as análises se concentram no contexto em questão, enraízamse nele, mas o estudo também é retrospectivo e projetivo: ancorado em um conhecimento crítico da herança histórica do país, Freire aponta os caminhos que a sociedade brasileira poderia tomar e onde eles poderiam levá-la, a depender, entre outros fatores, do modelo educativo-educacional que se constituísse

\footnotetext{
${ }^{2}$ Em um texto recém-publicado no jornal eletrônico Diário do Centro do Mundo, Leonardo Boff, um dos mais importantes desses teólogos escreveu: "[...] discutíamos ecumenicamente, acompanhados por um pequeno grupo de cientistas, inclusive de Paulo Freire, sobre temas relevantes do mundo e da Igreja [...]".

${ }^{3}$ Paulo Freire esteve por oito anos consecutivos à frente da divisão de educação e cultura do SESI-Pernambuco, e atuou por outros dois anos em sua Superintendência (FREIRE, 2001, p. 14).

Educação em Revista|Belo Horizonte|v.36|e233695|2020
} 
a partir de então. E, em suas palavras: "Nunca, no Brasil, teremos vivido condições mais propícias para uma revisão de nossa educação, em termos de autenticidade, como as de hoje, apesar de todas as contradições que vêm caracterizando a nossa atualidade" (FREIRE, 2001, p. 57). Assim, o trabalho é projetivo, e as proposições do autor fundamentam-se em uma abordagem conjuntural e histórica.

O caráter do escrito é analítico, ao encontrar elos entre o passado e o seu presente, mas também prospectivo e propositivo, sem esvaziar-se em fórmulas de um pretenso manual de ação educativa, aliás, pretensão completamente contrária a tudo que se propôs o pensador pernambucano. Freire não apresenta uma proposta estritamente pedagógica, ou, como na análise de Libâneo (1993), a sua teoria não tem uma proposta didática explícita. As reflexões do autor trazem uma série de concepções filosóficas, sociológicas e antropológicas com o objetivo de incitar, de provocar o leitor-educador a fazer ele mesmo as suas, a partir de uma posição considerada fundamental: a problematização crítica da realidade na qual se inserem concretamente os homens. Segundo Freire (2001, p. 09), "não nos será possível nenhum verdadeiro equacionamento de nossos problemas, com vistas a soluções imediatas ou a longo prazo, sem nos pormos em relação de organicidade com nossa contextura histórico-cultural”. A análise que recai sobre o equacionamento dos problemas precisa, necessariamente, dirigir-se à construção de uma relação de organicidade "que nos ponha imersos na nossa realidade e de que emerjamos criticamente conscientes" (FREIRE, 2001, p. 09. Grifos meus). A partir daí, lança-se o desafio à construção de propostas pedagógicas comprometidas com as demandas específicas de cada contexto.

Deter-se-á o presente artigo, a partir daqui, nos aspectos centrais texto de Paulo Freire (2001), com atenção aos elementos contextuais que propiciaram as suas reflexões. Serão igualmente analisadas as projeções do autor para o futuro que se lhe anunciava, bem como as contribuições teóricas que fazem de Educação e atualidade brasileira uma chave para a compreensão da sociedade, da política e da educação brasileiras também nos dias de hoje.

Seis décadas separam a obra aqui analisada e a atual conjuntura nacional, e os entraves a um modelo de educação progressista, emancipadora, libertadora, democrática, enfim, intensificam-se e as desilusões se agravam. Freire, além de fornecer subsídios teóricos para o seu tempo, continua a iluminar a "nova" realidade, que reserva semelhanças e pontos de aproximação com aquela que ele tanto conheceu. Se os "pontos de estrangulamento" (FREIRE, 2001, p. 11) do processo de democratização do país nos anos 1950 e 1960 se aparentam aos atuais, como se pode inferir pela leitura da obra, é também com Freire que se deve resgatar a esperança na educação do e com o oprimido, por sua vez, potencial mola propulsora da irrupção de uma autêntica luta democrática.

\section{O CONTEXTO, O PROBLEMA E AS POTENCIALIDADES DA “ATUALIDADE BRASILEIRA"}

O pensamento freiriano emergiu em um contexto muito específico, repleto de potencialidades, mas também de contradições, caraterizado discursivamente pelo que se convencionou chamar de nacionalismo desenvolvimentista. A conjuntura política e social do Brasil dos anos 1950 e a reconfiguração pela qual passavam, naquele momento, as formas e as relações de trabalho no país fornecem elementos capazes de lançar luzes sobre o constructo teórico do pensador pernambucano, que via a educação, embora condicionada pelo contexto histórico-social, como uma força em potência, capaz de dinamizar a inserção direta das massas trabalhadoras nos processos decisórios nacionais, o que representaria a construção de um modelo de nação, de fato, democrático. O autor estava atento à ambivalência dos processos educacionais, que poderiam representar tanto uma "força estabilizadora" quanto um "fator de mudança" (FREIRE, 2001, p. 10).

O Brasil passava pelo seu processo tardio industrialização, e a construção de Brasília, sua nova capital, representou a materialidade do desenvolvimento apregoado, cujo marco simbólicopropagandístico fora sintetizado no lema "50 anos em 5", do plano de metas do governo Kubitschek. Os intelectuais do ISEB inserem-se no projeto do nacionalismo desenvolvimentista como protagonistas na elaboração de seu ideário, apesar das já apontadas dissonâncias entre as orientações políticas de seus membros e dos caminhos distintos assumidos pelo governo federal naquele momento (ABREU, s/d; 
BRESSER-PEREIRA, 2004; PAIVA, 2005; TOLEDO, 1998). Alinhado com os “isebianos", para Freire (2001, p. 11-12), era inaceitável que uma sociedade que se industrializava e se democratizava insistisse "em oferecer uma educação intensamente verbal e palavrosa", que acabava por se fazer "um dos obstáculos ao nosso desenvolvimento econômico, bem como à nossa democratização".

De fato, o autor estava atento às antinomias e aos pontos de estrangulamento dentro da atualidade que comprometiam a democratização do país, e via, no agir educativo, um instrumento pelo qual a sociedade brasileira poderia concretizar a sua tarefa prioritária, que deveria consistir "na diminuição dessas antinomias e até na sua extinção" (FREIRE, 2001, p. 13). Mas a disputa de forças estava posta e, com efeito, o que poderia culminar na plena democratização do país acabaria por se desvirtuar em um golpe de Estado que refreou aquele processo por meio da instauração de uma Ditadura Civil-Militar em nosso país (1964-1985), uma ruptura democrática brusca, que irrompeu, vale dizer, cinco anos após Freire formular, no livro aqui analisado, as suas inquietações e a sua esperança.

Para Freire (2001), homem não é um ser ao qual a realidade natural-cultural se sobrepõe, tampouco é mecanicamente determinado por ela; do mesmo modo, a ela não é superposto, ou seja, não é a ela alheio, mas nela se insere de modo radicalmente dialético. Sendo natural, o homem não é redutível à natureza (como os animais irracionais), da mesma forma como não se reduz à cultura por ele criada. A dialeticidade não-determinística entre o homem, a natureza e a cultura marca as concepções antropológico-filosóficas de Freire, e traz uma consequência teórica importante: os seres humanos, todos, devem se inserir em processos educativos-educacionais capazes de torná-los conscientes dessa dialeticidade, o que tende a gerar novas disposições mentais e consequências culturais, sociais e políticas inéditas. Na prática, as massas precisam se inserir nos processos decisórios nacionais, razão de ser de uma pedagogia que, anos mais tarde, Freire (2011) denominaria do oprimido. Não obstante, a relutância por parte dos governos e de outras instituições e grupos em propiciar essa inserção constituía uma das grandes antinomias da atualidade problematizada pelo autor. O problema da necessária inserção das massas nos processos decisórios nacionais não estava sendo enfrentado, sequer aventado, na e por aquela sociedade que se industrializava e se desenvolvia economicamente, crescia em projeção e, ao menos supostamente, se democratizava.

A sociedade brasileira vivia um drama marcado por uma forte contradição: o país se industrializava e as projeções de crescimento econômico e de desenvolvimento apontavam para um horizonte até então inaudito, não obstante, sofria os efeitos da crônica "inexperiência democrática" (FREIRE, 2001, p. 12) do seu povo. Eis o cerne temático de Educação e atualidade brasileira: dadas as potencialidades do contexto, da atualidade, a educação seria um dos meios pelos quais se poderia superar essa antinomia, mas uma educação completamente distinta daquela que se oferecia no país até então. Era necessário reinventá-la, era urgente construir uma "educação para a democracia" (FREIRE, 2001, p. 83), democracia que, segundo o autor, "antes de ser forma política é forma de vida" (FREIRE, 2001, p. 76) caracterizada pela apropriação do homem por si mesmo, pelo seu envolvimento responsável com os problemas da sua comunidade e do seu país, pela luta contra todas as formas de assistencialismos paternalistas e opressões.

Essa nova educação, ou esse inédito "agir educativo" (FREIRE, 2001, p. 11), deveria promover a "inserção participante" (FREIRE, 2001, p. 10) das massas nos processos decisórios nacionais, inserção crítica e responsabilizadora de sujeitos silenciados e não raro paternalisticamente assistidos. O modelo educativo a se elaborar deveria ser capaz de manter as mulheres e os homens em "relação de organicidade" (FREIRE, 2001, p. 09) com a conjuntura social, e não aliená-las/los, como acontece pelos modelos conservadores da "escola tradicional". Assim, a criação de condições favoráveis a que todas as pessoas passassem da "vida inautêntica" para a "vida autêntica", razão de ser de uma educação para a justiça social, deveria dar o tom da nova práxis, do novo agir educativo.

Vale destacar que em Educaşão e atualidade brasileira já aparecem aspectos basilares do pensamento da maturidade de Freire. Com seu característico estilo apaixonado de escrita, o autor defende uma educação que se realize horizontalmente, dialogicamente e com o bomem:

Interessou-nos sempre, e desde logo, a experiência democrática através da educação. Educação da criança e do adulto. Educação democrática que fosse, portanto, um trabalho do homem com 
o homem, e nunca um trabalho verticalmente do homem sobre o homem ou assistencialistamente do homem para o homem, sem ele (FREIRE, 2001, p. 14).

Difícil negar a razoabilidade dessas considerações; mais difícil ainda pensar que, sim, elas foram, lato sensu, negadas.

\section{ANTINOMIA FUNDAMENTAL E DISPOSIÇÕES MENTAIS DO POVO BRASILEIRO}

A atualidade, como entende Freire (2001), é um processo, e mais, processo dinâmico, cumulativo, condicionado pelas experiências do momento presente e pela herança histórica, tanto do passado recente quanto do mais remoto. O conhecimento crítico desse processo revela as suas antinomias e o modo como foram geradas as disposições mentais dos sujeitos, e ainda possibilita a superação das contradições que marcam a consciência do homem nacional.

$\mathrm{Na}$ impossibilidade de elencar e analisar toda a gama de antinomias da atualidade brasileira, o autor enfatiza a antinomia fundamental a partir da qual aquelas se capilarizam: o contraste entre a "inexperiência democrática" e a "emersão do povo na vida pública nacional" (FREIRE, 2001, p. 26. Grifos do autor). O primeiro polo dessa antinomia capital, por assim dizer, é um dos produtos nefastos da herança colonial brasileira, perpetuado pelos processos políticos verticais presentes em toda a história nacional, e o segundo uma potencialidade histórica. Essa emersão, para se fazer democrática, logo, não mais antinômica, deveria se orientar por um agir educativo de caráter emancipatório.

O autor descreve concretamente a perniciosa ambiguidade das consciências forjadas nesse ambiente cultural tão contraditório. A "inexperiência democrática" que marca essas consciências explica, entre tantos outros fatos, a prática eleitoral dos que votam "em candidato ao Executivo, ao mesmo tempo em que, para o Legislativo, em outro, de linha política oposta", da mesma forma como "atendendo-se a condições de parentesco ou de amizade ou de gratidão", o povo adere a um "candidato reconhecidamente inferior, contanto que não se fira o amigo, o parente ou o obsequiador com 'ingratidão' de se lhe negar o voto" (FREIRE, 2001, p. 27). Ambas as situações ainda são comuns, não se circunscrevem ao período em que Freire escreveu a obra aqui analisada. O primeiro exemplo revela o desconhecimento geral acerca dos impasses provocados entre o conflito de interesses no campo das lutas políticas; o segundo dá ênfase à prática da "camaradagem", que sobrepõe pretensões individuais a interesses coletivos, de classe social; ambos denotam que se vota em pessoas, ou na representação que se tem delas, não em projetos, dos quais os eleitos devem ser tão somente executores. Como consequência, enormes contingentes populacionais aderem acriticamente a projetos político-partidários opostos aos interesses do seu grupo social e internalizam uma discordância irrefletida de projetos mais democráticos e até mesmo o ódio contra os sujeitos que os encabeçam, dicotomia que continua a marcar as escolhas eleitorais de grande parte da população brasileira, sobretudo das suas frações mais pobres.

Saindo do campo estritamente político-partidário encontramos outros exemplos de manifestações daquela antinomia fundamental, exemplos de casos comuns, tanto na atualidade analisada por Freire quanto na nossa. Aquilo que talvez se possa chamar de desorganização ideológica do homem nacional representa um dos mais marcantes traços da nossa "inexperiência democrática". E aqui é necessário cuidado, pois o conceito de ideologia nos coloca em um campo bastante nebuloso, muitas das vezes eivado por discussões que escapam ao rigor científico e filosófico e se enveredam por sendas estranhas, corrompidas por interesses políticos, com o fim único de macular determinadas discussões e conjuntos de proposições. Essa forma contaminada da palavra ideologia é costumeiramente utilizada por grupos conservadores com o intuito de deslegitimar as lutas sociais progressistas, o que ocorre, por exemplo, quando aqueles grupos e suas lideranças alcunham de "ideologia de gênero" o que, de fato, se trata da questão de gênero, ou quando se denuncia o "viés ideológico" da "esquerda" negando-se o "enviesamento ideológico" das "direitas" em nome de sua suposta e pretensa neutralidade e imparcialidade.

\footnotetext{
${ }^{4}$ Por representação, baseado em Bourdieu (2006) e Chartier (1990; 1991), entendo a percepção socialmente condicionada da realidade, percepção manifesta nos discursos e orientadora das práticas dos sujeitos.

Educação em Revista|Belo Horizonte|v.36|e233695|2020
} 
Ao tratar do conceito de ideologia, Freire o estava compreendendo quase como uma ética, e também como um conjunto coerente de ideias e diretrizes que deveria ser capaz de levar à organização e à mobilização dos grupos sociais em prol de pautas verdadeiramente democráticas. É nesse sentido que o pensador pernambucano se filia a Hélio Jaguaribe, quando este defende a necessidade de se construir uma "ideologia do desenvolvimento", e que este é um problema de "educação e organização ideológica" (JAGUARIBE, 1957, p. 53 apud FREIRE, 2001, p. 31) ${ }^{5}$. E é também essa a sua defesa ao empregar a expressão "ideologia do desenvolvimento", como o fez Vieira Pinto, no sentido de planejamento coletivo do desenvolvimento nacional (PINTO, 1956), isto é, uma orientação sistemática a um fim determinado guiada por princípios coletiva e democraticamente estabelecidos. Segundo Freire (2001, p. 97), é a "análise crítica de nossa problemática [...] que irá dando à escola de que precisamos a tarefa de 'ideologizadora' [...] no processo de nosso desenvolvimento". Da mesma forma, o autor entedia ser urgente a elaboração de uma "ideologia" da educação técnica (FREIRE, 2001, p. 109) para que esta modalidade de ensino fosse capaz de promover a ampliação do quadro técnico capacitado do país, e assim atender as demandas oriundas do seu desenvolvimento, contudo, sem que seu objetivo fosse o de simplesmente formar "mãode-obra" qualificada: a formação técnica deveria ser, igualmente, uma "educação para a democracia" (FREIRE, 2001, p. 83), nesse sentido, ideológica ${ }^{6}$.

Outra pauta que denota a incoerência popular é a da reforma agrária, "sem cuja solução continuaremos dificultando a nossa crescente democratização" (FREIRE, 2001, p. 30). Ao deslegitimar os movimentos sociais de luta pela terra e mesmo ao demonizar esses movimentos por meio de deturpações midiáticas e da divulgação seletiva de notícias, os setores conservadores da sociedade acabam por obter a adesão das camadas populares a sua defesa da política latifundiária, muitas das vezes sustentada pela prática criminosa da grilagem de terras. Verdadeira cooptação dos pobres acontece também quando, novamente caindo no canto da sereia liberal/conservadora, no discurso da "eficiência" e da "honestidade" da iniciativa privada, põem-se a favor das privatizações das empresas e dos serviços estatais: a ausência de uma formação crítica e democrática impede a população de ver com objetividade que quanto mais se privatiza o que é público, menos ela tem acesso a bens e serviços.

A antinomia fundamental analisada por Freire, e que ainda parece caracterizar a nossa atualidade, manifesta-se, igualmente, na adesão popular a posições ultraconservadoras, também em sentido moral, que flertam com ideários neofascistas ou protofascistas, como prefere Souza (2017), e fomentam o ódio contra os grupos sociais com menor representação política, como os pobres, os negros, a população LGBTQI+, as mulheres (GALLEGO, 2018).

Segundo Freire (2001, p. 57), "diminuir e até superar algumas dessas antinomias" faz parte das "tarefas" da educação, mas de uma educação "autêntica", identificada com a "contextura da sociedade". Esse modelo educativo deve ser construído de modo a romper com a nossa herança cultural antidemocrática e potencializar a promoção do país de "ser semicolonial, alienado" em "ser nacional, autêntico" (FREIRE, 2001, p. 29). E essa autenticidade incorporada pelas mulheres e pelos homens é o que o autor, ancorado em Guerreiro Ramos, entende por nacionalismo, "que é mais do que o amor à terra e a lealdade aos símbolos que a representam. É tudo isso e o projeto de elevar uma comunidade à apropriação total de si mesma" (RAMOS, 1957, p. 29 apud FREIRE, 2001, p. 56).

Por sua vez, a apropriação total da si mesma pela comunidade demanda "transitividade" e "criticidade", conceitos fundamentais em Freire. A consciência de um povo é marcada por "disposições mentais" (FREIRE, 2001, p. 13) que levam a variadas formas de percepção da realidade e de atuação sobre ela. Algumas dessas disposições são predominantes em certas épocas e espaços, pois as comunidades e as populações dos países não compõem massas uniformes e indiferenciadas. A fim de traçar um quadro

\footnotetext{
${ }^{5}$ Em alguns momentos deste texto lanço mão de citações dentro de citações; essas menções indiretas têm o objetivo de explicitar a intensidade com que Freire vinha sendo influenciado por determinados autores.

${ }^{6}$ Foge ao escopo deste trabalho discutir o complexo conceito de ideologia. Contudo, interessa mencionar que, do nosso ponto de vista, ele não é o mais adequado para englobar aquilo que Paulo Freire defende em sua argumentação, ainda que o pensador pernambucano tenha contextualizado e referenciado seu uso. 
geral dessas disposições, o autor trata longamente de três formas de consciência, a intransitiva, a transitivo-ingênua e a transitivo-crítica ${ }^{7}$, bem como do movimento de promoção do homem via educação.

Necessariamente relacional e histórico, o ser humano se constitui mental, espiritual e socialmente pelo contato com a natureza, com a cultura e com os demais seres humanos (FREIRE, 2001). A experiência desses múltiplos e cotidianos contatos o leva à abertura em níveis diferenciados a novas experiências, em um processo que pode tanto torná-lo mais humano quanto desumanizá-lo. São esses níveis de abertura - ou de permeabilidade, como prefere o autor - que caracterizam as diversas manifestações da consciência.

Conforme Freire (2001, p. 34), a "consciência intransitiva representa um quase incompromisso entre o homem e sua existência"; é o estado de alienação, de fechamento dos seres humanos em "áreas estreitas de interesses e preocupações". Quanto à consciência transitivo-ingênua, embora represente um avanço qualitativo em relação à intransitiva, caracteriza-se "pela simplicidade na interpretação dos problemas", pelo saudosismo, pela "transferência da responsabilidade e da autoridade", o que abre ensejo para o surgimento de propostas perigosamente messiânicas no campo político, e só pode ser superada pela criticidade, que é marca da consciência transitivo-crítica, predominante nos "autênticos regimes democráticos" (FREIRE, 2001, p. 34), e que é característica do homem dialogal e em emancipação. Esta, por sua vez, não surge espontânea e automaticamente, mas carece de um fazer pedagógico orientado para a promoção da consciência transitivo-ingênua ao nível crítico, sob o risco iminente de declínio à massificação, uma espécie de hipertrofia da intransitividade. Conforme o autor, o nível de "transitivação" das consciências (FREIRE, 2001, p. 36) se dá na razão direta do grau de industrialização das diversas regiões do país, sendo as regiões mais "agrícolas" aquelas com maior tendência à intransitividade. Uma educação contextualizada e dialógica, que descentralize o palavrório e os abstracionismos e academicismos (FREIRE, 2001, p. 11), seria a única capaz de promover a consciência do homem e de afastar o perigo da massificação.

A democratização, como a própria expressão sugere, é um processo, e não é algo dado, pronto, mas uma possibilidade, enquanto tal, presente em qualquer circunstância histórica, embora em determinados momentos essa possibilidade pareça estar mais próxima de sua realização - caso dos fins da década de 1950, na leitura de Freire. O embate entre as forças que objetivam refrear esse processo, a bandeira "reacionária", "entreguista", e as forças que o procuram dinamizar, a bandeira do "nacionalismo" (FREIRE, 2001, p. 55), é componente das lutas de classes, em sentido marxista. Entretanto, Freire parecia estar certo de que o polo do nacionalismo venceria essa luta: "Toda ação, que tente retardar - porque deter não nos parece possivel - esta marcha, é reacionária e perigosa" (FREIRE, 2001, p. 19. Grifo meu). Aqui o autor soa profundamente otimista quanto aos destinos do país, posição teórica que, em uma leitura superficial, pode soar como contendo ares teleológicos de uma Filosofia da História ortodoxamente hegeliano-marxista, para os desavisados, quiçá um tanto positivista até, embora em vários momentos Freire procure evidenciar a importância da construção de um agir educativo que oriente os homens em direção a um futuro indeterminado.

\section{UMA GENEALOGIA DA NOSSA INEXPERIÊNCIA DEMOCRÁTICA}

Marca essencial do pensamento de Paulo Freire é a forma coerente como o otimismo cultural e o senso de realidade se apresentam em seus escritos. A leitura do contexto, sua análise e os projetos do autor são plenos de notas esperançosas e lúcidas. Freire é categórico ao afirmar que a superação de nossa inexperiência democrática não se reduz "a um puro e simples problema de educação", antes, a constituição de uma educação autêntica apresenta-se na dependência de "condições institucionais", de um verdadeiro "clima cultural" capaz de condicionar um "agir educativo" inédito e orgânico (FREIRE, 2001, p. 60). Isso desmente qualquer interpretação apressada e simplista do pensamento freiriano, que poderia atribuir ao autor uma concepção ingenuamente idealizada e redentorista da educação. Com efeito,

\footnotetext{
${ }^{7}$ Esses conceitos não são propriamente de Freire, como revela ao afirmar que eles vinham sendo debatidos, na década de 1950, por Vieira Pinto, Guerreiro Ramos, Roland Corbisier, entre outros (FREIRE, 2001, p. 32). Contudo, Freire os emprega de modo original, em um rearranjo teórico que também apresenta ares gramscianos. 
ele é enfático: "Não estamos realmente emprestando sentido messiânico à escola. Estamos, sim, afirmando e reclamando o seu papel democratizador" (FREIRE, 2001, p. 97).

Esse "clima cultural", ou, como prefere Barbu (1956, p. 53) apud Freire (2001, p. 60), essa "atmosfera cultural específica", apresenta-se como "condição externa" da promoção da democratização, que, por sua vez, depende também de algo que nos faltava nos fins da década de 1950 - e ainda nos falta -, isto é, uma "organicidade educativa" em consonância com aquela "condição externa", ou com nossas "condições institucionais" (FREIRE, 2001, p. 60).

As contradições presentes na sociedade brasileira e a antinomia fundamental já apresentada neste texto, encontram suas raízes nas origens coloniais do país. São as nossas marcas do "ontem" (FREIRE, 2001, p. 25). É interessante observar que o autor elabora a sua argumentação respaldado em obras de cientistas sociais, como Caio Prado Júnior, Djacir Menezes, Gilberto Freyre, João Lúcio Azevedo, Nélson Werneck Sodré e Oliveira Viana, mas também em escritos de cronistas, por assim dizer, que passaram pelo país em séculos anteriores, caso do artista alemão Johann Moritz Rugendas (ou João Maurício Rugendas, como ficou conhecido no Brasil), da escritora, também alemã, Ina Von Binzer, dos religiosos Antônio Vieira e André João Antonil, do escritor e comerciante inglês John Luccock e do naturalista francês Auguste Saint-Hilaire. O jurista, jornalista e político paraibano Aristides Lobo é outra dessas referências.

Freire traça um retrospecto analítico da formação histórica, cultural e política da sociedade brasileira, e entende a nossa inexperiência democrática como um dos produtos desse complexo processo, caracterizado pela ausência de "condições necessárias à criação de uma consciência participante" (FREIRE, 2001, p. 61) no homem nacional. A colonização "fortemente predatória", o interesse meramente comercial da metrópole portuguesa e a escravidão do nativo e do africano revelam que não houve, da parte dos colonizadores, a "intenção de criar na terra descoberta, uma civilização" (FREIRE, 2001, p. 61).

As terras brasileiras não teriam, no primeiro momento, despertado nos colonizadores intenções de povoamento, tampouco suas riquezas os atraíram tanto, ao menos em comparação com as do mundo Oriental, o que não favoreceu a construção de uma relação de "organicidade com a colônia" (FREIRE, 2001, p. 62). A escravidão e o regime da grande propriedade, seja da fazenda, do engenho e dos próprios seres humanos que nesses espaços trabalhavam, ocasionaram o mutismo brasileiro, entendido por Freire (2001, p. 64) como "a posição meramente expectante do nosso homem diante do processo histórico nacional”.

A estrutura política, econômica e cultural do Brasil colônia impediu que o nosso homem experienciasse uma "vivência comunitária" (FREIRE, 2001, p. 66), único meio pelo qual se poderia constituir nele um espírito verdadeiramente democrático. Já que as disposições democráticas são incorporadas por meio das formas de relação estabelecidas entre os homens, "com essa política de colonização, com seus moldes exageradamente tutelares, não poderíamos ter tido experiências democráticas" (FREIRE, 2001, p. 70). Não se constituiu no povo brasileiro uma consciência de grupo, pelo contrário, as condições histórico-culturais da formação do país produziram disposições individualistas ainda arraigadas nas consciências e manifestas nas atitudes dos homens e das mulheres. Os processos de formação do Brasil não possibilitaram "a criação do homem 'solidarista', só recentemente emergindo das novas condições culturais que vivemos, mas indeciso nessa solidariedade e necessitando, por isso mesmo, de educação fortemente endereçada neste sentido" (FREIRE, 2001, p. 85). Em outras palavras, se a colonização do Brasil impediu a formação de um senso comunitário no homem nacional, a atualidade analisada por Freire, plena de contradições, mas também de possibilidades, estava a fazer emergir, incipientemente, esse senso, que carecia, no entanto, de organicidade educativa para romper com o individualismo historicamente herdado e para constituir o novo "clima cultural" caracterizado por uma maior solidariedade entre as pessoas.

\footnotetext{
${ }^{8}$ Freire fez uso do texto de Barbu (1956) em língua inglesa, e fez as suas citações diretas também neste idioma. As traduções para o português dos trechos citados foram feitas pelo organizador da obra (FREIRE, 2001), e aparecem em notas de rodapé. São essas mesmas traduções que transcrevo nas citações do presente artigo.

Educação em Revista|Belo Horizonte|v.36|e233695|2020
} 
Desde o início da colonização europeia, no século XVI, a sociedade brasileira não viu emergir condição concreta de possibilidade para a construção de uma cultura democrática. Com efeito, toda a atmosfera nacional fora marcada pela verticalidade política, administrativa, social e econômica. Entretanto, com o surgimento de novas "condições faseológicas" - expressão de Berlinck (1954, p. 09), largamente utilizada por Freire - as possibilidades surgem e se ampliam: no final da década de 1950, o "impacto da industrialização" (FREIRE, 2001, p. 71) era a sua marca maior. Caberia um senso de oportunidade, um olhar atento e um captar do momento da ação, com a consciência de que as forças conservadoras também aproveitariam o momento para, novamente, refrear o curso da democratização.

Vemos aqui um tríplice movimento analítico em Freire, marcado pela retrospecçãoatualização-projeção. O autor reconstrói a formação histórica do país e elabora uma espécie de genealogia da nossa inexperiência democrática, insere essa reflexão histórica no momento pelo qual passava o país e vislumbra a real possibilidade da construção de uma educação que atue em relação de organicidade com as "condições externas", a seu ver, propícias à democratização política e cultural, encarnadas naquele momento, sobremaneira, nos processos de industrialização que eclodiam nos nossos grandes centros urbanos. O fazer democrático exige a incorporação de "disposições mentais democráticas" (FREIRE, 2001, p. 86), ou, nos dizeres de Viana (1955, p. 195) apud Freire (2001, p. 75), de "condições culturais e psicológicas" específicas, as quais, para serem gestadas, carecem de uma "estrutura de mentalidade, ou seja, certas experiências, atitudes, pré-noções e crenças partilhadas por todos, ou por uma ampla maioria", segundo Barbu (1956, p. 13) apud Freire (2001, p. 77).

A construção de um país democrático, caracterizado pela forte presença da justiça social, carece daquela incorporação de disposições mentais necessárias a esse fim, de um "estado de espírito" (FREIRE, 2001, p. 71) inédito em nosso povo, cujas condições de surgimento se faziam presentes de forma intensa à época em que Freire defendia a sua tese aqui analisada: "Só a partir, repita-se, dos primeiros surtos de industrialização, implicando modificações de nossa economia, mais fortemente neste século, é que se pode, na verdade, falar de um legítimo ímpeto popular” (FREIRE, 2001, p. 73).

Cabe ainda ressaltar que houve veleidades de democratização na história do Brasil, frustradas, todavia, pelo fato de terem sido "importadas" de outras partes do mundo, sobretudo da Europa, sem nenhum tipo de respeito às idiossincrasias nacionais e sem nenhuma inclusão do "povo massa" nesse processo. Para Freire (2001, p. 75), foi superposta "a uma estrutura economicamente feudal e a uma estrutura social em que o homem quedava vencido, esmagado e mudo, uma forma política e social, cujos fundamentos exigiam, ao contrário do mutismo, a dialogação, a participação, a responsabilidade, política e social".

Após apresentar a antinomia fundamental que marca a sociedade brasileira, da qual se capilarizam um sem número de contradições e desigualdades, Freire defende que as suas raízes se encontram no processo de formação histórica do país e na forma como foram constituídas as estruturas político-administrativas e culturais nacionais ao longo desse processo. As disposiçoes mentais do homem nacional, ou seus estados de espírito (FREIRE, 2001, p. 71), forjaram-se em uma atmosfera autoritária, excludente, incapaz de propiciar a esse homem o aprendizado da democracia, sua vivência experiencial, único meio pelo qual é possível incorporá-la. Identificados o problema e as suas causas, Freire vislumbra possíveis alternativas de intervenção capazes de mitigar, quiçá de eliminar por completo aquela antinomia, alternativas que devem ser construídas com o povo e pelo povo. Como educador e como pensador da educação, o que o autor se propõe é refletir acerca da tomada de posição "que deve assumir o nosso agir educativo face a essa mesma antinomia fundamental” (FREIRE, 2001, p. 26), tema pertinente, também, à nossa atualidade.

\section{UM HORIZONTE EM ABERTO: O NOVO ÍMPETO POPULAR E O PAPEL DOS PROCESSOS EDUCATIVOS}

Apresentada a antinomia fundamental da momento analisado - a nossa "inexperiência democrática" em dissonância com a "emersão do povo na vida pública nacional” (FREIRE, 2001, p. 79) - e levantadas as raízes histórico-culturais do primeiro polo desse antagonismo, o autor discute o problema principal da educação daquele momento, e em todos os seus níveis, "o de sua inadequacidade 
com o clima cultural", e define o escopo de uma educação democrática: "Parece-nos que uma das fundamentais tarefas da educação brasileira, vista sob o ângulo de nossas condições faseológicas atuais, será, na verdade, a de criar disposições mentais no homem brasileiro, críticas e permeáveis" (FREIRE, 2001, p. 79), com que ele possa definitivamente superar a sua inexperiência democrática.

A industrialização, embora tenha se dado tardiamente no país em relação aos países do hemisfério norte, e mesmo em relação a outros países da América Latina, a crescente urbanização de várias áreas do território nacional e a expansão da economia indicavam que o país já contava com "condições culturais favoráveis" a uma "nova postura de nossa escola". Tais condições, "se aproveitadas e 'trabalhadas' pela educação, em algum tempo mais, darão surgimento a novas disposições mentais, agora democráticas, porque forjadas em experiências de participação" (FREIRE, 2001, p. 99).

A escola precisa assumir-se como uma das instâncias - obviamente, ela não é única, mas é a mais fundamental delas - responsáveis pela emersão participativa, crítica e democrática do povo na vida pública nacional. Contudo, tal tarefa estava "a exigir toda uma revisão em nosso arcaico sistema educacional" (FREIRE, 2001, p. 92), ou seja, a escola brasileira precisava se tornar orgânica, algo inédito na educação oferecida no país.

Freire dedica um amplo espaço da obra aqui analisada para criticar a não-organicidade da escola brasileira com as condições sociais, políticas, econômicas e culturais, e dirige sua crítica a todos os níveis educacionais, ou seja, à escola primária, secundária, ao ensino de grau superior e, sobretudo, às escolas de formação do professor primário9. O autor insiste em sua crítica com o objetivo explícito de fazer com que permaneça no entendimento do leitor a forma como a escola vinha reproduzindo a antinomia fundamental da atualidade brasileira por ele retratada tão sistematicamente; da mesma maneira, relembra, constantemente, como tal antinomia é produto de uma herança histórica de longo prazo. Assim, também nesse ponto, o movimento retrospecção-atualização-projeção, marca essencial da tese de Freire, manifesta-se como recurso discursivo coerente com o conjunto do escrito.

Em linhas gerais, a crítica de Freire à educação oferecida no Brasil, incluídos os cursos de formação de professores, toca no aspecto fundamental da sua não-organicidade com a realidade em todos as suas dimensões. A educação por ele criticada é uma educação superposta à realidade, isto é, um modelo educativo que oferece aos educandos uma série de informações de caráter abstrato, sem vínculo com a realidade, principalmente, com os problemas da atualidade, "problema agudos", enfatiza Freire (2001, p. 111). Desde o currículo, que deveria ser tornar "plástico" (FREIRE, 2001, p. 103), moldável à problemática do real, e regionalizado, atinente às necessidades geográficas, até à prática dos educadores, tudo se encontrava em defasagem em relação aos demais processos vividos pela sociedade brasileira. Assim, deve caber à educação a assunção de uma postura problematizadora, que eduque a partir da problematização da realidade local, regional, nacional, sem a mera entrega de respostas prontas para as tensões sociais, políticas, econômicas e culturais que devem ser apresentadas como problemáticas aos educandos, desnaturalizando-as, tratando-as com estranhamento, e sistematicidade; assim, os educandos não estariam a fazer meros exercícios de resolução de problemas, mas estariam sendo convocados a serem partícipes da resolução factual dos problemas discutidos nos espaços educativos. E nisso consiste o aprendizado da democracia, reponsabilidade da educação escolar e extraescolar (FREIRE, 2001, p. 114), aprendizado "enraizado no conhecimento concreto da sociedade" (MANNHEIM, 1946, p. 12 apud FREIRE, 2001, p. 82).

Mais do que criticar e apresentar as contradições inerentes aos processos educativos, Freire (2001, p. 88) faz uma verdadeira denúncia do "descaso ainda ostensivo dos poderes públicos, sobretudo federais", pelo problema da escola pública brasileira, inclusive e principalmente no que tange aos recursos financeiros a ela destinados, que fazem dela uma "escola, hoje ainda mal preparada materialmente, sem equipamentos, sem adequado material didático, sem condições higiênicas, sem vitalidade, sem verba", e conclui que, com tal escola, será impossível "ajudar o nosso educando a inserir-se no processo de democratização e de nosso desenvolvimento". E um importante passo nesse sentido seria o

\footnotetext{
${ }^{9} \mathrm{O}$ ensino primário, com duração de quatro anos, corresponde, conforme nomenclatura atual, aos anos iniciais do ensino fundamental, que hoje vai do $1^{\circ}$ ao $5^{\circ}$, e o ensino secundário corresponde aos quatro anos finais do ensino fundamental mais os três anos do ensino médio (então, respectivamente, curso ginasial e curso colegial).

Educação em Revista|Belo Horizonte|v.36|e233695|2020
} 
descentralização administrativa e pedagógica da educação, sua regionalização, a sua entrega ao cuidado administrativo dos municípios e à construção do seu currículo pelas comunidades diretamente ligadas às unidades escolares, único meio de se construir processos educativos enraizados na problemática local, e não na mera palavra (FREIRE, 2001, p. 88), defesa teoricamente amparada, sobretudo, em Anísio Teixeira (1957).

Em sua crítica-denúncia do descompasso da educação brasileira em relação aos processos sociais, políticos, econômicos e culturais pelos quais passava o país, Freire elenca uma série de aspectos derivados desse descompasso, ou a ele diretamente relacionados. Embora o limite do espaço deste artigo impeça uma discussão pormenorizada de cada um desses aspectos, penso que interessa mencioná-los, ainda que sumariamente.

A escola brasileira reforçava a nossa inexperiência democrática e comprometia o potencial processo de democratização nacional, em antinomia com a necessidade fundamental daquele momento: a de formar "homens que se integrem neste impulso de democratização que nos caracteriza atualmente" (FREIRE, 2001, p. 91). E isso decorria da superposição daquele modelo educacional à realidade na qual os homens se encontravam inseridos, mais que isto, enraizados: o aluno, afirma Freire (2001, p. 93), "tem raízes que se fincam em espaços que lhe dão cores", e é desses espaços, problematizando-os, significandoos, que o processo educativo deve partir, pois desconhecê-los e ignorá-los em nome de um saber superposto ao real "implica dificilmente conhecer, compreender e ajudar" os sujeitos, necessariamente históricos, embora nem sempre criticamente conscientes de sua historicidade.

As instituições escolares em sintonia com o desenvolvimento econômico de uma nação não podem ser "apenas centros de alfabetização de nossos meninos, mas centros onde formem hábitos de solidariedade e de participação" (FREIRE, 2001, p. 91), isto é, onde se eduque para a democracia. E tal escola é também uma instância educadora das famílias dos educandos, segundo o autor, para quem importa "que a escola de nossa atualidade eduque seu aluno e suas famílias no sentido da responsabilidade social e política, de que somos tão carecentes ainda" (FREIRE, 2001, p. 96. Grifo meu), o que somente se dará por meio de projetos desenvolvidos pela escola, e que tenham como objetivo incluir as famílias em seus processos decisórios. Cabe à escola, primeiramente, efetuar um movimento centrífugo, de saída de si mesma em direção às famílias e à comunidade, em clima de "dialogação", pois "ao travar relações que devem ser cada vez mais íntimas com as famílias de seus alunos, deve ela criar um clima propício à participação, à ingerência daquelas no seu destino" (FREIRE, 2001, p. 93). O movimento se faz, posteriormente, centrípeto, de atração das famílias e da comunidade para o seu interior, onde viva de forma experiencial a democracia, irradiando essa experiência novamente para os processos sociais mais amplos, externos à escola.

A reflexão abre espaço para que Freire apresente explicitamente outro tema que se lhe tornaria caro: o da educação de adultos. Para o autor, a escola deve se alongar "em autênticos centros de educação de adultos", educação "para a responsabilidade social e social", a qual consiste em "uma das enfáticas exigências da nossa democracia em elaboração ou em aprendizagem” (FREIRE, 2001, p. 96).

Entre outras contribuições, Freire denunciou o caráter excludente do ensino secundário de sua época e mostrou como esse seguimento de ensino se prestava a tornar a universidade refratária aos pobres, tornando-a quase que exclusivamente privilégio das elites econômicas do país. Conforme Freire (2001, p. 108), "o que vem acontecendo com a maioria esmagadora dos que procuram o ginásio brasileiro para a sua afirmação social é uma dolorosa frustração", e por duas razões: 1) por não conseguirem "atravessá-lo", isto é, concluí-lo, não conseguem chegar aos níveis mais elevados de ensino, no caso, o curso colegial e o nível superior; 2) no ginásio, o estudante "nada ou quase nada encontra que lhe possibilite uma atividade prática na sua comunidade", pois o aprendizado de profissões não era objetivo desse nível de ensino, completamente distanciado das "condições faseológicas" analisadas pelo autor. O caráter do ensino secundário era absolutamente seletivo, destinado "ao preparo das nossas diminutas classes de lazer e de mando", nas palavras de Anísio Teixeira (1957, p. 40), textualmente citadas por Freire (2001, p. 104), "preparo" que conferia legitimidade à manutenção dos privilégios dessas classes.

Deve-se observar ainda que Freire defendia necessidade da oferta massiva de ensino técnico e profissionalizante nas escolas secundárias brasileiras, mas com o cuidado de que esse ensino não se prestasse meramente a formar mão de obra qualificada para o mercado de trabalho. Para o autor, era 
urgente a constituição de "quadros técnicos" para que atingíssemos a "produtividade indispensável ao nosso desenvolvimento", contudo, a formação técnica deveria caminhar ao lado da crítica, pois era imperativo que o pessoal técnico fosse capaz de planejar, projetar e dirigir os rumos do desenvolvimento (FREIRE, 2001, p. 109).

As contradições apontadas por Freire em Educação e atualidade brasileira resistiram ao tempo e, de diferentes modos, ainda caracterizam os processos educativos. Entretanto, essas contradições são passíveis de superação, como mostrou o autor, e o próprio processo histórico - a atualidade - propicia novas possibilidades de reflexão-ação, de envolvimento humano na luta contra as estruturas sociais opressoras que têm aparelhado a escola em função da manutenção dos privilégios de determinados grupos sociais. Obviamente, nenhuma luta acontece sem a resistência do poder público, dos setores conservadores da sociedade, da própria escola e seus agentes, e mesmo dos grupos que deveriam estar mais diretamente interessados nessas transformações - as camadas populares em suas várias frações. Não obstante, nenhuma postura reacionária (como a chamaria Freire) pode abrir espaço para a mera resiliência, a aceitação do real como algo dado e inexorável e o conformismo.

A escola se configura no tempo conforme parâmetros estabelecidos pelos grupos sociais que, no embate sócio-histórico de forças, tornam-se dominantes e a aparelham no intuito de perpetuar essa dominação, logo, sua estruturação não se dá "por acaso" (FREIRE, 2001, p. 98). A perspectiva de Freire é a da historicidade, do processo, da cultura em elaboraşão, e se, em sua perspectiva, os fins da década de 1950 propiciavam, mais que outro momento anterior, a "rebelião popular" (FREIRE, 2001, p. 28), o fato é que a sociedade nunca é, mas sempre é em trânsito, portanto, aberta a possibilidades que se realizarão naquele mesmo embate de forças do qual não se pode nem se deve fugir.

Paulo Freire conseguiu sustentar com rigor teórico a sua utopia, compreendida não como impossibilidade, mas como inconformismo com o real e como projeto, e estava ciente quanto à "dramaticidade" que a indeterminação histórica e as lutas de forças encerram. A transitividade ingênua das consciências não pode ser promovida automaticamente, sem um agir educativo, à transitividade crítica, o que nos leva sempre ao angustiante risco da massificaşão, da fanatização da consciência popular. Para Freire (2001, p. 82) “é exatamente o 'conhecimento concreto' de nossa sociedade ou de aspectos mais importantes de sua atualidade, que nos adverte de certos perigos para nossa democracia em aprendizagem", vale dizer, ainda em aprendizagem nesse outro século, razão pela qual necessitamos conhecer a fundo esses "perigos" e alimentar as "forças" que nos podem levar à democratização. Em 1959, conforme leitura de Freire, as forças em disputa estavam contidas nos processos de industrialização, de crescimento econômico e de urbanização de certas regiões do país. Resta-nos encontrá-las nos inúmeros processos hoje vividos, por exemplo, na informatização, na automação, na virtualização, na expansão das tecnologias da informação e no acesso a tais tecnologias. A esperança não pode ser perdida, mas é necessário estarmos atentos aos riscos que continuam a correr o "legítimo ímpeto popular" (FREIRE, 2001, p. 73).

\section{UMA LENTE PARA ENXERGARMOS A NOSSA ATUALIDADE}

Sessenta anos, e a nossa educação ainda não se constituiu em um meio formativo capaz de levar o povo à participação ativa nos processos decisórios nacionais - o que deveria ser o seu papel preponderante, insistia Freire. Foge aos objetivos do presente texto discutir a função da escola e da educação a partir de perspectivas teóricas diversas. No entanto, parte-se aqui de uma adesão deliberada à concepção freiriana segundo a qual, espaço socializador por excelência, a escola deve promover experiências dialógicas sistemáticas a partir das quais seja constituída entre os alunos, em um aprendizado paulatino e experiencial, uma mentalidade democrática. Cabe à educação, escolar ou não, levar o homem a agir com espírito comunitário. Ressalta-se aqui, pela noção de educaşão não-escolar, que o "aprendizado existencial da democracia" (FREIRE, 2001, p. 115) precisa se dar, também, em todos os demais espaços compartilhados pelos homens, na família, nas empresas, nas associações de moradores de bairros, nos sindicatos, nas igrejas...

À exceção de experiências educativas e educacionais alternativas dispersas, o Brasil insiste em oferecer ao povo uma educação completamente submissa à lógica autoritária e alienante do modo 
capitalista de produção. Os paternalismos e as formas de instrumentalização da instituição escolar se agravaram, a opressão se perpetuou e se tornou mais intensa (ora por mecanismos explicitamente repressores, ora pela via legal-institucional, respaldada por narrativas inverídicas em torno de sua pseudoneutralidade), os pobres, sobretudo, continuam sendo sistematicamente silenciados, inclusive com o injustificável discurso da incapacidade deliberativa das classes populares, discurso, por sua vez, comumente assumido por essas classes, lamentavelmente aceito e assumido por elas, e que teve como outra grave consequência a delegação das grandes decisões nacionais aos políticos profissionais, aos magnatas, aos burocratas, aos tecnocratas, aos operadores do capital, supostamente mais competentes e aptos para esse fim. Tema que, por sinal, fará parte de todo o conjunto da obra de Freire é, precisamente, o da confiança no homem como pressuposto democrático fundamental: "a democracia e a educação democrática - educação de que precisamos - se fundam ambas, precisamente, na crença no homem" (FREIRE, 2001, p. 90). Mais uma vez, Freire se ancora em Anísio Teixeira, para quem urgia que tivéssemos "o elementar bom senso de confiar no país e nos brasileiros, entregando-lhes a direção dos seus negócios" (TEIXEIRA, 1957, p. 53 apud FREIRE, 2001, p. 84). A afirmação de que o povo "não tem competência para gerir os destinos da nação", concepção tão lamentavelmente presente no senso comum brasileiro, não deixa de fazer algum sentido; com efeito, como um povo pode ter "competências" para as quais não foi capacitado por uma educação que o ajudasse a incorporar disposições verdadeiramente participativas e democráticas? $\mathrm{O}$ aprendizado da democracia se dá pela experiência, inclusive e principalmente, pelos erros cometidos no seu processo de aprendizagem, razão pela qual o povo precisa ser inserido no debate democrático. Conforme Freire (2001, p. 41) serão "os erros do povo, a sua aceitação a fórmulas prejudiciais a seus interesses às vezes mais imediatos, que refletidos depois em termos práticos irão levá-lo à superação daquele procedimento e à exigência de outros". E o debate democrático deve ser fundado, repita-se, na "crença em que ele [o homem] não só pode, mas deve discutir os seus problemas. Os problemas de sua comunidade. Os problemas de seu trabalho. Os problemas da própria democracia" (FREIRE, 2001, p. 90).

Aos pobres é conferida pelo poder público uma escola, salvas parcas exceções, repleta de carências, dado o permanente descaso dos governos com os grupos sociais que mais dependem dele, e que não raras vezes se encontram em situação de profunda desumanização. As classes médias, sobretudo as suas frações mais elevadas, e as elites têm acesso a uma escola pertencente à iniciativa privada, que, em sua quase absoluta totalidade, adestra crianças e jovens, mecaniza-os, robotiza-os para que decorem fórmulas prontas e "macetes" capazes de levá-los ao ingresso nos cursos superiores de maior proeminência, prestígio social e com maior potencial de conferir um retorno econômico em curto prazo aos pais-investidores. Este é, igualmente, um modelo desumanizante de educação. De forma geral e apesar dos poucos avanços - poucos, embora significativos, vale dizer, como as políticas públicas de reservas de vagas para pretos, pardos e indígenas nas universidades -, é fato que a escola ainda oportuniza timidamente a promoção dos grupos sociais subalternos.

Ao identificar a circunstância propícia para dar início à democratização plena nos processos de industrialização e urbanização de determinadas áreas do Brasil, bem como no crescimento econômico vivido pelo país no fim da década de 1950, Freire apontou duas possibilidades inerentes à disputa entre forças sociais opostas, uma democrática, outra reacionária. Certamente, o autor não poderia prever que este segundo polo sairia vencedor, e de modo tão arbitrário e violento, via instauração de uma Ditadura Civil-Militar cujos ranços ainda lubrificam as engrenagens do tempo presente. Da mesma maneira, não haveria como se prever os destinos do país caso a completa reformulação de nossa educação, tal como propôs Freire, houvesse acontecido naquele momento. Entretanto, é possível afirmar que a inserção massiva e orgânica do povo nos processos decisórios nacionais certamente teria dado tons, no mínimo, menos autoritários àquele momento.

A relevância epistemológica das análises retrospectivas consiste, sobretudo, no fato de tais análises evidenciarem a indeterminação histórica das atualidades, repita-se, compreendidas como processos, e um debruçar crítico sobre a nossa atualidade revela como ela guarda fortes semelhanças com aquela analisada por Freire (2001). As mesmas antinomias persistem e hipertrofiadas, além de outras tantas originadas no decorrer dos anos. 
Um dos efeitos mais perversos da nossa "inexperiência democrática", ainda tão fortemente presente e acentuada, são as inúmeras desigualdades que assolam o Brasil: desigualdade social, econômica, política, étnico-racial, escolar, de gênero, desigualdade de acesso aos bens sociais, enfim, desigualdades que poderiam ser amenizadas ou mesmo extintas, caso fosse oferecida a todos uma educação capaz de gerar no homem "disposições para agir conscientemente nos interesses de sua comunidade" (FREIRE, 2001, p. 29).

Outra mostra de nossa persistente inexperiência democrática é o silenciamento do povo, o seu mutismo. Essa posição expectante do povo brasileiro, historicamente tem se alterado em determinados momentos, motivada por estímulos específicos, embora quase sempre de modo não-orgânico, acrítico, vindo a se tornar, não voz autêntica, mas um "movimento de turbulência". Logo que cessados, o mutismo volta a se fazer presente sob a forma de "alheamento à vida pública" (FREIRE, 2001, p. 64). Atualmente, as redes sociais virtuais têm sido um dos âmbitos principais em que se manifesta essa "turbulência". Diariamente, inúmeras pessoas expressam seus posicionamentos políticos, éticos, artísticos, morais, religiosos, sociais, etc., em sítios virtuais de relacionamento, amparadas pela ilusão de estarem, de fato, fazendo ecoar uma voz que lhes seja própria. No entanto, muitas dessas pessoas são acriticamente cooptadas por grupos sociais e políticos cujos interesses são antidemocráticos, e, sem condição de desconstruir os argumentos desses grupos, acabam difundido uma visão de mundo incondizente com a justiça social. A grande mídia impressa, o rádio e a televisão, muitas das vezes, compunham a via difusora de mão única de concepções antipopulares. $\mathrm{O}$ acesso acrítico e não-orgânico das massas à internet intensifica o problema, pois, além de receberem tais conteúdos, elas ainda contribuem com a sua divulgação, quase sempre daquela forma turbulenta, o que, embora aparentemente soe paradoxal, é ainda uma manifestação do mutismo, agora mascarado pelo tom de "algazarra" (FREIRE, 2001, p. 71), o que confere ao povo a fria ilusão de que sua palavra está sendo realmente dita. Pode-se pressupor que Freire, se vivo fosse, entenderia que uma educação para a democracia precisa orientar as massas no sentido do acesso crítico aos meios sociais de comunicação e às tecnologias da informação. Parece inevitável que as redes sociais virtuais continuem sendo espaços de debate, o que exige que esse debate passe a ser, não mais algazarra e destilação de ódios diversos, mas dialogação (FREIRE, 2001) com vistas à resolução conjunta de nossos problemas pelo nosso povo, que precisa passar a se sentir responsável por eles.

Igualmente antinômica é a forma como o povo participa das decisões políticas. A incoerência político-partidária marca as concepções de todo um enorme contingente populacional, ainda incapaz, porque não educado, não formado para isto, de perceber que o "bem comum" não pode estar verdadeiramente ligado à pauta de agentes políticos e de partidos que representam os interesses de um grupo muito específico e restrito: o das elites econômicas. Um povo que adere acriticamente a projetos contrários aos seus próprios interesses de classe é um povo ainda marcado por aqueles traços mais opressores e silenciadores do nosso processo de colonização, tão marcadamente retratado por Freire.

Tanto em 1959 quanto hoje, embora de forma bastante geral e dadas as especificidades de cada momento histórico, a nossa "inexperiência democrática" em contradição com a "emersão do povo na vida pública nacional" parece ser a antinomia fundamental a ser superada por um agir educativo voltado para a promoção da consciência de nossa população ao nível da criticidade e da organicidade, e isto ainda demanda, como demandava, na visão do jovem Freire, uma completa revisão do nosso processo educativo e de nossa escola.

Indo além, em sentido conceitual, apesar de todas as dificuldades postas pela nossa atualidade, e em razão mesma dessas dificuldades, o momento parece propício para que se continue a pensar em uma proposta concreta de educação destinada a levar a população oprimida à conscientização quanto ao seu pertencimento de classe. Interessa levar o povo a perceber criticamente a sua posição na estrutura social e as causas históricas e sociais das desigualdades entre as classes. A ocultação dessas desigualdades - ou a referência a elas como meras "diferenças" - acarreta o seu aprofundamento. As incoerências político-partidárias e a adesão a projetos contrários aos interesses da classe a que se pertence, entre inúmeras outras contradições, nascem exatamente dessa falsa percepção reforçada pelo discurso das elites, discurso segundo o qual os interesses são "comuns", os governos visam ao "bem geral da nação" e "todas as pessoas são iguais em direitos e deveres". Por outro lado, perceber-se pertencente a uma determinada classe social significa identificar-se com outros sujeitos de igual condição e com os interesses 
desses sujeitos, o que reduz ou mesmo elimina o risco de oposições internas e cisões que obstaculizam a luta pelas demandas comuns da classe e geram uma forma de violência horižntal (FREIRE, 2011). Afirma Freire (2001, p. 33-34) que a criticidade "implica a apropriação crescente pelo homem de sua posição no contexto", e implica, igualmente, "a libertação do homem de suas limitações e indigências [...] pela consciência delas".

Uma educação para a consciência de classe, como chamarei, deve ser efetivada no sentido de levar esperança aos desesperançados e de fomentar a luta por transformações profundas. A relativização das concepções fatalistas e imobilizadoras é uma nota presente em toda a obra do pensador pernambucano - por exemplo, Freire $(1978 ; 1992 ; 1996 ; 2001 ; 2011)$-, bem como a convicção de que, por serem históricos, os homens podem modificar a sua realidade via engajamento consciente, problematizador, crítico, dialogal, democrático: "numa democracia, mesmo e principalmente em aprendizagem como a nossa, serão inautênticas as soluções para o povo, que não partam do povo" (FREIRE, 2001, p. 22).

Uma educação capaz de levar o homem a reconhecer-se pertencente a uma classe social historicamente oprimida precisa ser igualmente capaz de gerar nesse homem o senso de responsabilidade, sem o qual não pode haver engajamento coletivo em prol das transformações sociais. Sendo responsabilizadora, a educação almejada deve atuar também no sentido de promover a autoestima dos grupos sociais oprimidos, desmascarando os discursos arbitrários que inculcam nesses grupos o sentimento de inferioridade cultural e de incapacidade de ingerência nos destinos da comunidade e do país. Em outras palavras, à denúncia da opressão e à responsabilização coletiva pela resolução dos problemas comuns deve se somar uma postura de afirmação cultural das populações oprimidas.

As possibilidades apresentadas neste encerramento, inspiradas pela leitura de Freire (2001) e aplicadas ao momento presente, a nossa atualidade, são introdutórias. A complexidade do problema exige um esforço muito maior que o aqui empregado, e exige o envolvimento coletivo de educadores, pais, estudantes, trabalhadores, movimentos sociais organizados, agentes políticos, homens e mulheres com interesse em construir propostas educativas voltadas para a justiça social. Entretanto, parte-se aqui do pressuposto de que o conjunto da obra de Freire pode ser um instrumento para a construção de tais propostas, não literalmente abstraídas do pensamento do autor, mas adaptadas às necessidades das circunstâncias atuais, ou para as condições faseológicas atuais, como costumava insistir. Importa que tais propostas, seguindo o educador pernambucano, descentralizem o "conteúdo", comumente "verboso", "engessado", "pedante", e deem centralidade à problematização dialógica do real em todas as suas dimensões. Do ponto de vista prático e pedagógico, ainda em consonância com Freire, que as técnicas possam ser construídas localmente, com atenção às especificidades regionais e culturais com as quais os sujeitos mantêm (ou devem manter) uma relação radicalmente dialética. Do mesmo modo, não são negadas as diversas formas de resistência a modelos educativos como o proposto por Freire. A pretensão única é que este texto possa contribuir minimamente com o debate em torno das questões levantadas.

O Brasil é marcado pelo profundo contraste entre as possibilidades históricas e a suposta incapacidade (na verdade, incapacitação) do seu povo para assumir democraticamente o controle e o direcionamento dessas possibilidades. A persistência desse contraste no tempo e sua presença em todo o território nacional evidenciam o esforço violento que fazem os grupos sociais dominantes para que os dominados se mantenham democraticamente inexperientes, motivo pelo qual é necessário levar ao homem uma proposta educativa crítica, no intuito de "aumentar-lhe o grau de consciência dos problemas de seu tempo e de seu espaço" (FREIRE, 2001, p. 31). O desafio é hercúleo, mas suas dimensões não podem eclipsar os sonhos coletivos e a esperança de construção uma sociedade mais justa. A leitura da obra de Paulo Freire faz avivar esses sonhos e essa esperança.

\section{REFERÊNCIAS}

ABREU, Alzira Alves de. O ISEB e o Desenvolvimentismo. Centro de Pesquisa e Documentação de História Contemporânea do Brasil. Fundação Getúlio Vargas. s/d. Disponível em $<$ https://cpdoc.fgv.br/producao/dossies/JK/artigos/Economia/ISEB>, acesso 14 de janeiro de 2020. 
BARBU, Zevedei. Democracy and dictatorship: their psycology and patterns of life. London: Routledge Kegan-Paul Ltd., 1956.

BERLINCK, E. L. Fatores adversos na formação brasileira. São Paulo: IPSIS, 1954.

BOFF, Leonardo. Dois papas: dois modelos de homem, dois modelos de Igreja. Diário do Centro do Mundo, edição de 04 de janeiro de 2020. Disponível em <https://www.diariodocentrodomundo.com.br/doispapas-dois-modelos-de-homem-dois-modelos-de-igreja-por-leonardo-

boff/?fbclid=IwAR1oXBQEULelG-n8vHQGaCrzNzmzfdMV16M-Y19frbTvicGOfrWde_T3akQ>, acesso em 15 de janeiro de 2020.

BOURDIEU, Pierre. A ilusão biográfica. In: AMADO, Janaína; FERREIRA, Marieta de Moraes (Orgs.). Usos \& abusos da história oral. Rio de Janeiro: Editora da Fundação Getúlio Vargas, 2006. p. 183-191.

BRASIL. Decreto-Lei ñ 4.244, de 09 de abril de 1942. Lei Orgânica do Ensino Secundário. Disponível em $<$ http://www.planalto.gov.br/ccivil_03/decreto-lei/1937-1946/Del4244.htm>, acesso em 02 de janeiro de 2020.

Decreto-Lei n $n^{0}$ 8.529, de 02 de janeiro de 1946. Lei Orgânica do Ensino Primário. Disponível em <https://www2.camara.leg.br/legin/fed/declei/1940-1949/decreto-lei-8529-2-janeiro-1946-458442publicacaooriginal-1-pe.html>, acesso em 02 de janeiro de 2020.

Decreto $n^{\circ}$ 37.608, de 14 de julho de 1955. Institui no Ministério da Educação e Cultura um curso de altos estudos sociais e políticos, denominado Instituto Superior de Estudos Brasileiros, dispõe sobre o seu funcionamento e dá outras providências. Disponível em <https://www2.camara.leg.br/legin/fed/decret/1950-1959/decreto37608-14-julho-1955-336008-publicacaooriginal-1-pe.html>, acesso 14 de janeiro de 2020.

BRESSER-PEREIRA, Luiz Carlos. O conceito de Desenvolvimento do ISEB rediscutido. Revista de Ciências Sociais, Rio de Janeiro, vol. 47, $\mathrm{n}^{\circ}$ 1, 2004, p. 49-84. Disponível em <http://www.scielo.br/pdf/dados/v47n1/a02v47n1.pdf>, acesso em 14 de janeiro de 2020.

BEISIEGEL, Celso Rui. Paulo Freire. Recife: Fundação Joaquim Nabuco; Editora Massangana, 2010.

BRIGHENTE, Miriam Furlan; MESQUIDA, Peri. Paulo Freire: da denúncia da educação bancária ao anúncio de uma pedagogia libertadora. Pro-Posições, Campinas, v. 27, n. 1 (79), jan./abr. 2016, p. 155-177. Disponível em <http://www.scielo.br/pdf/pp/v27n1/1980-6248-pp-27-01-00155.pdf>, acesso em 15 de janeiro de 2020 .

CHARTIER, Roger. A história cultural entre práticas e representações. Rio de Janeiro: Bertrand Brasil, 1990.

. O mundo como representação. Estudos Avançados, São Paulo, v. 11, n. 5, p. 173-191, 1991.

COSTA, José Junio Souza da. A educação segundo Paulo Freire: uma primeira análise filosófica. Theoria - Revista Eletrônica de Filosofia, Pouso Alegre, v. VII, n. 18, 2015, p. 72-88. Disponível em <http://www.theoria.com.br/edicao18/06182015RT.pdf>, acesso em 15 de janeiro de 2020.

FREIRE, Paulo. Os cristãos e a libertação dos oprimidos. Lisboa: Edições Base, 1978.

1992.

. Pedagogia da esperança: um reencontro com a pedagogia do oprimido. Rio de Janeiro: Paz e Terra, . Pedagogia da autonomia: saberes necessários à prática educativa. São Paulo: Paz e Terra, 1996.

. Educação e atualidade brasileira. São Paulo: Cortez; Instituto Paulo Freire, 2001.

. Pedagogia do oprimido. Rio de Janeiro: Paz e Terra, 2011.

GALLEGO, Esther Solano (Org.). O ódio como politica: a reinvenção das direitas no Brasil. São Paulo: Boitempo, 2018.

JAGUARIBE, Hélio. Condições institucionais do desenvolvimento. Rio de Janeiro: ISEB, 1957.

LIBÂNEO, José Carlos. Didática. São Paulo: Cortez, 1993. 
MANNHEIM, Karl. Diagnóstico de nuestro tiempo. México: Fondo de Cultura Económica, 1946.

MENDONÇA, Nelino José Azevedo de. A bumanização na pedagogia de Paulo Freire. 2006. 168 f. Dissertação (Mestrado em Educação). Universidade Federal de Pernambuco, Recife. 2006. Disponível em <https://repositorio.ufpe.br/handle/123456789/4507>, acesso em 15 de janeiro de 2020.

OLIVEIRA, Paulo César de. Fundamentos do pensamento de Paulo Freire. Três Corações: Ediarte, 2004.

PAIVA, Vanilda. Paulo Freire e o nacionalismo desenvolvimentista. São Paulo: Graal, 2005.

PINTO, Álvaro Vieira. Ideologia e desenvolvimento nacional. Rio de Janeiro: ISEB, 1956.

RAMOS, Guerreiro. Condições sociais do poder nacional. Rio de Janeiro: ISEB, 1957.

ROMÃO, José Eustáquio. Contextualização: Paulo Freire e o Pacto Populista. In: FREIRE, Paulo. Educação e atualidade brasileira. São Paulo: Cortez; Instituto Paulo Freire, 2001. p. XIII-XLVIII.

SOUZA, Jessé. A elite do atraso: da escravidão à Lava Jato. Rio de Janeiro: Leya, 2017.

TEIXEIRA, Anísio. Educação não é privilégio. Rio de Janeiro: José Olympio, 1957.

TOLEDO, Caio Navarro de. ISEB: fábrica de ideologias. Campinas: Editora da UNICAMP, 1998.

VIANA, Oliveira. Instituições politicas brasileiras. Rio de Janeiro: José Olympio, 1955.

ZITKOSKI, Jaime José. Paulo Freire \& a educação. Belo Horizonte: Autêntica Editora, 2010.

Submetido: $18 / 02 / 2020$

Aprovado: $20 / 08 / 2020$ 